\title{
EFEITO DA IDADE E DO REPOUSO PÓS-COLHEITA DE FRUTOS DE PEPINO NA SEMENTE ARMAZENADA ${ }^{1}$
}

\author{
CLAUDIO JOSÉ BARBEDO² , ADELIANA SAES COELHO BARBEDO², \\ JOÃO NAKAGAWA ${ }^{4}$ e OSVALDO SATO ${ }^{5}$
}

\begin{abstract}
RESUMO - Para avaliar os efeitos da idade e do repouso pós-colheita de frutos de pepino (Cucumis sativus L.) de duas cultivares, Pérola (espinhos escuros) e Rubi (espinhos claros), sobre as alterações na qualidade fisiológica das sementes durante o armazenamento, conduziu-se um experimento em Botucatu, SP e Bandeirantes, PR, durante quatro anos. Os frutos foram colhidos desde os 15 ('Rubi') ou 20 ('Pérola') dias até 45 dias após a antese, permanecendo em repouso pós-colheita por 0, 5, 10 e 15 dias, antes da extração das sementes. Antes e após dois e três anos de armazenamento (sacos de papel em ambiente de laboratório), foram retiradas amostras para avaliação do potencial germinativo e do vigor. Os resultados revelaram que sementes imaturas, retiradas de frutos colhidos precocemente (até 30 dias após a antese) e sem repouso pós-colheita, perderam totalmente a capacidade germinativa no segundo ano de armazenamento. Sementes que apresentavam valores iniciais de germinação mais elevados, as colhidas de frutos maduros (com ou sem repouso pós-colheita) ou de imaturos (30 e 35 dias de idade) com 10 a 15 dias de repouso pós-colheita, mantiveram valores acima de 70\% após três anos de armazenamento.

Termos para indexação: Cucumis sativus, maturação, germinação, conservação.
\end{abstract}

\section{EFFECT OF FRUIT AGE AND POST-HARVEST PERIOD OF CUCUMBER ON STORED SEEDS}

\begin{abstract}
Seeds from two cucumber (Cucumis sativus L.) cultivars, Pérola and Rubi, were evaluated in relation to physiological quality to verify the effects of age and postharvest period of fruits on seed storage potential. Fruits were harvested from 15 ('Rubi') or 20 ('Pérola') to 45 days after flowering and mantained in postharvest for $0,5,10$, and 15 days before seeds extraction, at room conditions. Seeds were dried and stored in paper bags at room conditions for two and three years. Before and after the storage periods, samples were taken to germination and vigour tests. Results showed that immature seeds (extracted from immature fruits - 30 days after flowering) without post-harvest period, did not germinate at second year. However, seeds with high germination at initial test, from either ripe fruits (40-45 days) or immature fruits (30-35 days) with 10 or 15 days of post-harvest, mantained high germination (more than $70 \%$ ) after three years of storage.
\end{abstract}

Index terms: Cucumis sativus, ripening, germination, conservation.

\footnotetext{
${ }^{1}$ Aceito para publicação em 16 de outubro de 1998.

${ }^{2}$ Eng. Agr, Dr., Seção de Sementes e Melhoramento Vegetal, Instituto de Botânica, Caixa Postal 4005, CEP 01061-970 São Paulo, SP. E-mail: cbarbedo@uol.com.br

${ }^{3}$ Enga Agra ${ }^{\mathrm{a}}$, Dra , Prefeitura do Município de São Paulo, DEPAVE, Av. Paulista, 2073 sobreloja, CEP 01311-000 São Paulo, SP.

${ }^{4}$ Eng. Agr., Dr., Prof. Titular, Dep. de Agricultura e Melhoramento Vegetal, Faculdade de Ciências Agronômicas, UNESP, CEP 18603-970 Botucatu, SP. Bolsista do CNPq.

${ }^{5}$ Eng. Agr., M.Sc., Prof. Adjunto, Dep. de Fitotecnia, Fundação Faculdade de Agronomia "Luiz Meneghel", Rod. BR 369, Km 54, CEP 86360-000 Bandeirantes, PR.
}

\section{INTRODUÇÃO}

Na produção de sementes de espécies oleráceas, a preocupação em atingir a máxima qualidade deve ser tão ou mais intensa que nas demais espécies cultivadas. Em algumas dessas espécies, inclusive, em função do custo unitário da semente ou do retorno econômico proporcionado, tal preocupação deve ser ainda mais intensa. Neste último caso, é importante lembrar o custo e as vantagens produtivas, qualitativa e quantitativamente dos híbridos que, nos últimos anos, têm ocupado espaços cada vez maiores do setor. Deve-se lembrar, também, que a produção 
dessas sementes híbridas, além de mais trabalhosa, envolve tecnologia mais avançada. Tudo isso resulta em maior custo das sementes exigindo, portanto, sua melhor qualidade física, físiológica e sanitária, bem como a maximização de seu uso. Assim, assumem grande importância não só a determinação dos melhores procedimentos de colheita das sementes, mas também condições de armazenamento que permitam comercializá-las por mais tempo.

Quanto ao armazenamento, há várias outras razões para sua utilização. Em alguns casos, pode não ser econômico multiplicar anualmente o estoque de sementes. Em outros casos, há necessidade de preservar bancos de germoplasma, e o valor do estoque de sementes muitas vezes está associado à taxa de multiplicação e pureza genética. Além disso, a qualidade das sementes de hortaliças é bastante influenciada por condições do ambiente durante sua formação, o que não assegura a qualidade das sementes em todos os ciclos de produção, podendo mesmo não existir produção em alguns anos. $\mathrm{O}$ armazenamento pode, então, regularizar o fornecimento e o padrão de qualidade dessas sementes. Outra particularidade no uso de sementes de espécies oleráceas é a irregularidade na demanda por sementes de cada cultura, dificultando a programação da produção e mantendo riscos constantes ao seu escoamento. Tal inconveniente também pode ser atenuado pelo armazenamento das sementes (George, 1985).

Entre as diversas variáveis que afetam a conservação das sementes durante o armazenamento, um aspecto importante a ser considerado diz respeito à sua própria qualidade inicial. Este, entre outros fatores, está diretamente relacionado com a proximidade entre o momento em que as sementes atingem a maturidade fisiológica e o momento em que são efetivamente colhidas. Quanto mais se antecipa a colheita das sementes em relação ao seu ponto de maturidade fisiológica, menor o seu vigor; por outro lado, quanto mais se atrasa a colheita após a maturidade, mais avançado estará o processo de deterioração. Em ambos os casos, o potencial de armazenamento das sementes é proporcionalmente reduzido, e estas ficam mais vulneráveis a condições adversas do ambiente de armazenamento (Carvalho \& Nakagawa, 1983; Bewley \& Black, 1985).
Portanto, quando se avalia a qualidade fisiológica das sementes durante o processo de maturação, buscando-se o melhor momento de colheita, devese avaliar também seu potencial de armazenamento. Este, além de seu efeito mais direto na perspectiva temporal de utilização das sementes, auxilia na própria determinação do momento em que as sementes adquiriram máxima qualidade fisiológica. De fato, é amplo o período em que, durante a maturação, as sementes apresentam elevada porcentagem de germinação. Porém, em apenas um curto espaço de tempo dentro deste período, as sementes apresentam elevada qualidade fisiológica, com ótimo vigor e maior potencial de armazenamento. Esse fato já foi observado, entre outras espécies, em diversas cucurbitáceas (Eguchi et al., 1958; Nerson \& Paris, 1988; Nerson, 1991; Demir \& Ellis, 1993). Além disso, os estudos realizados em maturação de sementes de cucurbitáceas, como em outras espécies de frutos carnosos, que envolvem colheita prematura com conseqüente repouso pós-colheita dos frutos para complementar a maturação das sementes (Araújo et al., 1982; Alvarenga et al., 1984; Pedrosa et al., 1987; Alvarenga et al., 1991; Barbedo et al., 1994), indicam que estas adquirem a mesma qualidade fisiológica das amadurecidas na plantamãe, desde que respeitado um tempo mínimo de repouso dos frutos. Essa observação é empregada, inclusive, para recomendação, na produção de sementes, quando os frutos são colhidos antes de sua maturação completa (Viggiano, 1990). Porém, não são realizados muitos estudos acompanhando a manutenção da qualidade das sementes durante seu armazenamento.

No presente trabalho, buscou-se avaliar o efeito da idade e do período pós-colheita de frutos de duas cultivares de pepino na qualidade fisiológica da semente durante o armazenamento.

\section{MATERIAL E MÉTODOS}

As sementes utilizadas neste trabalho foram obtidas de um cultivo realizado em Botucatu, SP, em 1988, sob dois túneis de plástico em arco, medindo, cada um, 20 metros de comprimento por 5 metros de largura, e altura de 2,65 metros no ponto mais alto. Em cada túnel foi semeada uma cultivar, sendo estas Pérola, de espinhos escuros, e Rubi, 
de espinhos claros, ambas do grupo denominado "Caipira". O solo da área foi classificado como Latossolo Vermelho-Escuro álico, textura média. O espaçamento foi de 1,0 m entre linhas por $0,5 \mathrm{~m}$ entre plantas. A condução da cultura seguiu as recomendações usuais para pepino tutorado, com irrigações diárias.

Colheram-se frutos de ambas as cultivares a cada cinco dias, a partir dos 15 ('Rubi') ou 20 ('Pérola') dias após a antese. Em cada época de colheita dividiu-se o total de frutos colhidos (12 por cultivar) em quatro grupos. O primeiro grupo teve extração imediata das sementes, caracterizando o período "zero" de repouso pós-colheita. Os demais grupos ficaram armazenados em ambiente natural de laboratório por 5, 10 e 15 dias (três frutos por período), para, então, extraírem-se suas sementes. Desta forma, constituiu-se um fatorial entre idades dos frutos na colheita x períodos de repouso pós-colheita, sendo 7 x 4 para 'Rubi' e 6 x 4 para 'Pérola'.

Em todos os períodos, a extração das sementes obedeceu à mesma metodologia. Os frutos foram abertos manualmente no sentido longitudinal, e as sementes, após a extração também manual, foram colocadas para fermentar naturalmente, por dois dias em recipiente de vidro, visando facilitar a remoção do envoltório mucilaginoso durante a posterior lavagem em água corrente. Após a lavagem, as sementes foram deixadas para secar à sombra, sobre papel. As sementes, então, foram acondicionadas em sacos de papel e armazenadas, até o segundo ano, no laboratório do Departamento de Agricultura e Melhoramento Vegetal da Faculdade de Ciências Agronômicas da UNESP, em Botucatu e, após o segundo ano, no laboratório do Departamento de Fitotecnia da Fundação Faculdade de Agronomia "Luiz Meneghel", em Bandeirantes, PR.

Logo após a secagem das sementes e também após dois e três anos de armazenamento, amostras foram retiradas para a realização dos testes de germinação e vigor. $\mathrm{O}$ teste de germinação foi realizado em germinador regulado para temperatura constante de $25^{\circ} \mathrm{C}$, em gerbox, sobre papel. Neste teste foram realizadas duas contagens, quatro e oito dias após a instalação (Brasil, 1976), sendo a primeira contagem considerada para avaliação do vigor. Nas avaliações foram registrados o número de plântulas normais, o número de plântulas anormais e o número de plântulas normais vigorosas, ou seja, aquelas com hipocótilo maior que $6 \mathrm{~cm}$ e sistema radicular bem desenvolvido. Com esses dados, calcularam-se a porcentagem de germinação (plântulas normais), a porcentagem de sementes germináveis (plântulas normais + plântulas anormais), a primeira contagem do teste de germinação e a porcentagem de plântulas vigorosas, estas duas últimas características consideradas como vigor.
O delineamento estatístico foi o de blocos casualizados, com quatro repetições de 50 sementes cada. Para análise estatística, os dados obtidos foram transformados para arc sen $(\%+0,5)^{0,5}$. As médias foram comparadas entre si pelo teste de Tukey a $5 \%$ de probabilidade.

\section{RESULTADOS E DISCUSSÃO}

Nas duas cultivares estudadas, a qualidade inicial das sementes teve expressiva influência na sua capacidade de armazenamento.

De maneira geral, sementes da cultivar Rubi que iniciaram o armazenamento com germinação superior a $70 \%$ conseguiram manter-se nesse nível, ou muito próximo a ele, após três anos (Tabela 1), com algumas exceções. Por outro lado, sementes que iniciaram o armazenamento com germinação abaixo de $50 \%$ chegaram ao terceiro ano com germinação nula ou próxima da nulidade.

$\mathrm{Na}$ cultivar Pérola parece ter ocorrido algum problema com a germinação na avaliação inicial (provavelmente alguma dormência das sementes), pois foi inferior à do segundo ano. Essa falha na germinação das sementes recém-extraídas dos frutos, porém já submetidas à secagem, ocorreu de forma bastante irregular entre as parcelas e assemelhou-se aos resultados observados por Watts (1938), por Zobel \& Davis (1949) e por Shifriss \& George Júnior (1965). Watts (1938) verificou que após 40 a 50 dias da extração a germinação do lote se regularizava e passava a atingir valores bem mais elevados. Descreve, ainda, que tal comportamento não é produto exclusivo do estádio de maturação em que se encontram as sementes. Em sementes de melão (Nerson \& Paris, 1988; Welbaum \& Bradford, 1991) e de melancia (Nerson \& Paris, 1988), espécies da mesma família do pepino, também se verifica dormência pós-colheita que desaparece com algum tempo de armazenamento. Nienhuis \& Lower (1981), que de forma semelhante observaram aumento na porcentagem e na velocidade de germinação após oito meses de armazenamento de sementes de pepino, relacionaram o fato à existência de modificações fisiológicas durante o armazenamento, sem, entretanto, confirmar se se devem à dissipação de inibidores da germinação ou a algum outro fator. Apesar dessa baixa germinação inicial, a partir do segundo ano pôde-se observar a mesma tendência apontada para a cultivar Rubi.

Pesq. agropec. bras., Brasília, v.34, n.5, p.839-847, maio 1999 


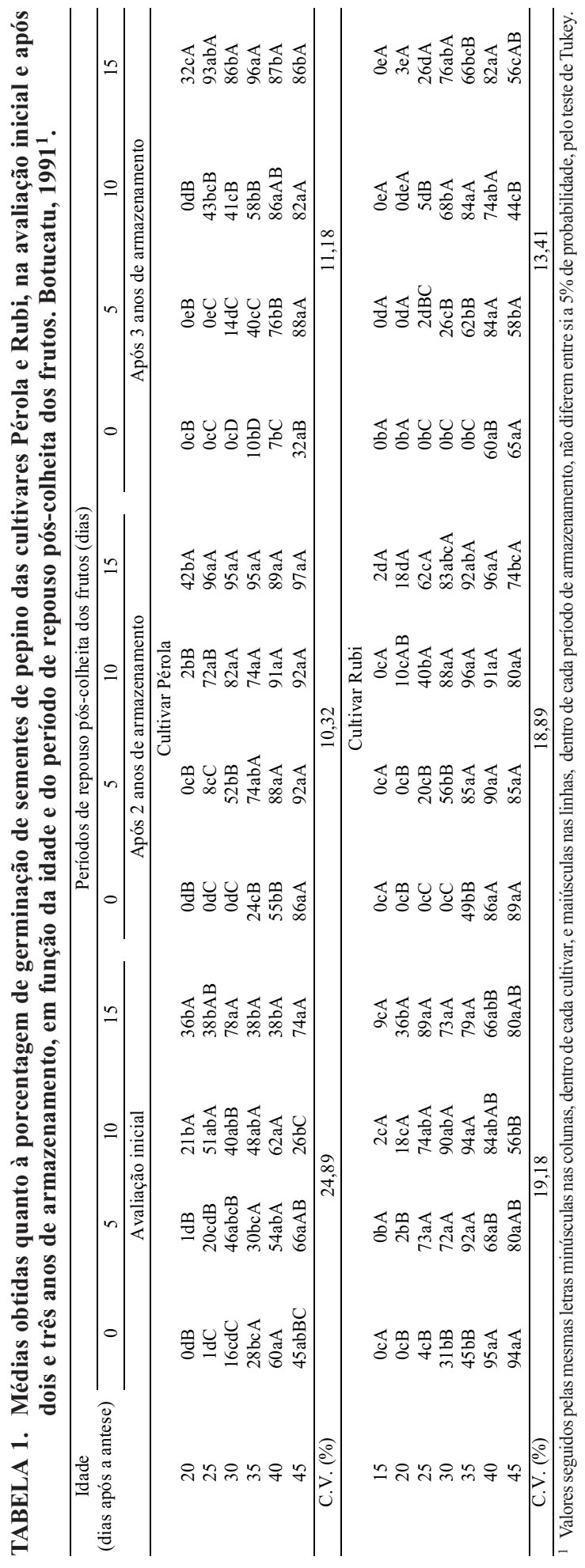

A maior perda do potencial de armazenamento observada em sementes imaturas, ou seja, as obtidas de colheitas precoces sem repouso dos frutos antes da sua extração (Tabela 1), foi verificada também por Nerson \& Paris (1988) não só quanto a pepino, mas também quanto a outras cucurbitáceas, como: abóbora, melão e melancia. Tal comportamento confirma as considerações feitas por Toledo \& Marcos Filho (1977) e Carvalho \& Nakagawa (1983) quanto à influência da qualidade inicial das sementes sobre seu potencial de armazenamento. Assim, a colheita precoce dos frutos com período insuficiente de repouso pós-colheita não permitiu às sementes atingirem o máximo vigor, resultando em menor período de conservação. Nerson \& Paris (1988) consideram, inclusive, que a maior redução na germinação em função do armazenamento pode ser devida ao tempo insuficiente para a formação do embrião, que, então, ainda estaria em desenvolvimento na semente colhida precocemente.

Por outro lado, o período excessivo de repouso pós-colheita dos frutos, nas colheitas mais tardias, resultando em menor germinação (Tabela 1), caracterizou o início da deterioração de suas sementes, que, então, também tiveram reduzido o seu potencial de armazenamento (Carvalho \& Nakagawa, 1983), fato este observado na cultivar Rubi.

Desde que as sementes apresentassem elevada porcentagem de germinação inicial, a sua capacidade de armazenamento não foi influenciada pela combinação entre idade e repouso pós-colheita dos frutos. Assim, tanto as sementes de frutos maduros (40 e 45 dias após a antese) sem repouso pós-colheita quanto as de frutos imaturos (30 e 35 dias) com algum repouso (10 a 15 dias) que permitisse elevar sua germinação para níveis acima de $70 \%$, independentemente da cultivar, conservaram-se bem até o terceiro ano, com comportamento muito semelhante entre elas (Tabela 1). Esses dados diferem dos obtidos por Eguchi et al. (1958), que, apesar da equivalência inicial em germinação das sementes de frutos maduros e de frutos imaturos, não suportaram, no último caso, armazenamento tão bom, com as diferenças aparecendo após o segundo ano de armazenamento.

Pode-se verificar, pelos resultados apresentados no presente trabalho, que a utilização de um período de repouso pós-colheita em frutos colhidos a um estádio mínimo de maturação, porém ainda imaturos, 
pode originar sementes de qualidade similar às amadurecidas na planta-mãe. A colheita dos frutos antes do ponto em que as sementes atinjam a maturidade fisiológica (obtida pelo repouso pós-colheita) evita o excesso de chuvas que pode, em alguns casos, ser prejudicial à maturação.

Enfim, se se considerar que a qualidade inicial das sementes é diferente em função do estádio de maturação em que se encontram, seu comportamento durante o armazenamento é também diferente, com melhor manutenção da qualidade das sementes colhidas mais próximas ao ponto de maturidade fisiológica. Bewley \& Black (1985) afirmam que quando o processo de maturação é interrompido por colheita prematura, o período de viabilidade das sementes no armazenamento pode ser afetado. Então, como tal fato não ocorreu nas sementes colhidas prematuramente aos 30 e 35 dias após a antese, porém mantidas no interior dos frutos por 10 a 15 dias, pode-se inferir que a maturação foi completada no interior dos frutos já colhidos (Tabela 1).

Um aspecto importante a se destacar é que, apesar de o comportamento genérico das cultivares ter sido semelhante quanto ao armazenamento, a cultivar Rubi apresentou sinais de que seu período propício à colheita, com fins de obtenção de sementes, é mais curto que o da cultivar Pérola (Tabela 1). Nesta última, obteve-se germinação superior a $90 \%$, após três anos de armazenamento, em sementes de frutos com apenas 25 dias de idade e repouso pós-colheita de 15 dias. Na cultivar Rubi, a elevada qualidade das sementes, com mesmo período de armazenamento, só foi obtida com frutos de 30 dias de idade e o mesmo repouso de 15 dias. Na outra extremidade, até os 40 dias de idade, em relação a frutos da cultivar Rubi, o repouso pós-colheita foi favorável à qualidade das sementes, mantendo sua elevada porcentagem de germinação. Mas, para frutos de 45 dias de idade, o repouso pós-colheita prejudicou a capacidade de armazenamento das sementes, levando a se supor que nesta idade as sementes já haviam atingido o ponto de maturidade fisiológica, e o repouso pós-colheita, portanto, correspondeu ao início do processo de deterioração. Já para a cultivar Pérola, o mesmo não ocorreu, pois até os 45 dias de idade dos frutos o repouso pós-colheita foi benéfico, o que indica que essas sementes, após a colheita e durante o repouso dos frutos, ainda não haviam iniciado o processo de deterioração.

Tal diferença no comportamento das cultivares pode explicar, em parte, as discordâncias verificadas por Eguchi et al. (1958), já relatados nesta discussão. Nesse contexto, é muito importante observar, pelos dados da Tabela 1, que as diferenças só apareceram após os três anos de armazenamento, principalmente na cultivar Rubi. Note-se, também, que nessa época (três anos) a porcentagem de plântulas vigorosas do teste de germinação (Tabela 2) acusou diferenças maiores tanto entre cultivares, com as sementes da cultivar Pérola apresentando maiores valores que os da cultivar Rubi, quanto entre idades e repousos dentro de cada cultivar, enfatizando a diferença na precocidade das cultivares, acima descrita, e mostrando longevidade diferenciada entre os genótipos. A diferença na longevidade das sementes de diferentes cultivares foi observada também por Ali et al. (1991), após 10 e 13 anos de armazenamento.

Ainda na Tabela 2, enquanto da cultivar Pérola obtiveram-se plântulas vigorosas, já em sementes de frutos com 20 dias de idade e 15 de repouso pós-colheita, na cultivar Rubi, o mesmo só ocorreu aos 25 dias de idade e 15 de repouso e, mesmo assim, esta com menos da metade da porcentagem daquela $(6 \%$ contra $18 \%)$. Na outra extremidade, também após três anos, a cultivar Pérola continuou apresentando plântulas vigorosas de sementes com até 45 dias de idade, somados a 15 de repouso pós-colheita dos frutos, enquanto na cultivar Rubi, com mesmo tempo $(45+15)$, já não havia sequer uma plântula vigorosa no teste de germinação. Mesmo com apenas 10 dias de repouso pós-colheita, em frutos com 45 dias de idade, as sementes da 'Rubi' não conseguiram gerar plântulas vigorosas naquele período do armazenamento. Note-se, ainda, que sem repouso pós-colheita, na idade final dos frutos (45 dias), as porcentagens de plântulas vigorosas de ambas as cultivares, tanto após dois quanto três anos de armazenamento, foram muito próximas ( $25 \%$ após dois anos e $9 \%$ após três anos). Entretanto, aplicados 10 a 15 dias de repouso pós-colheita, em 'Pérola' verificou-se ainda qualidade das sementes, ao passo que em 'Rubi' não houve mais plântulas vigorosas após três anos.

Avaliando-se ainda esse aspecto, que diferenciou as cultivares quanto à qualidade das sementes ar- 


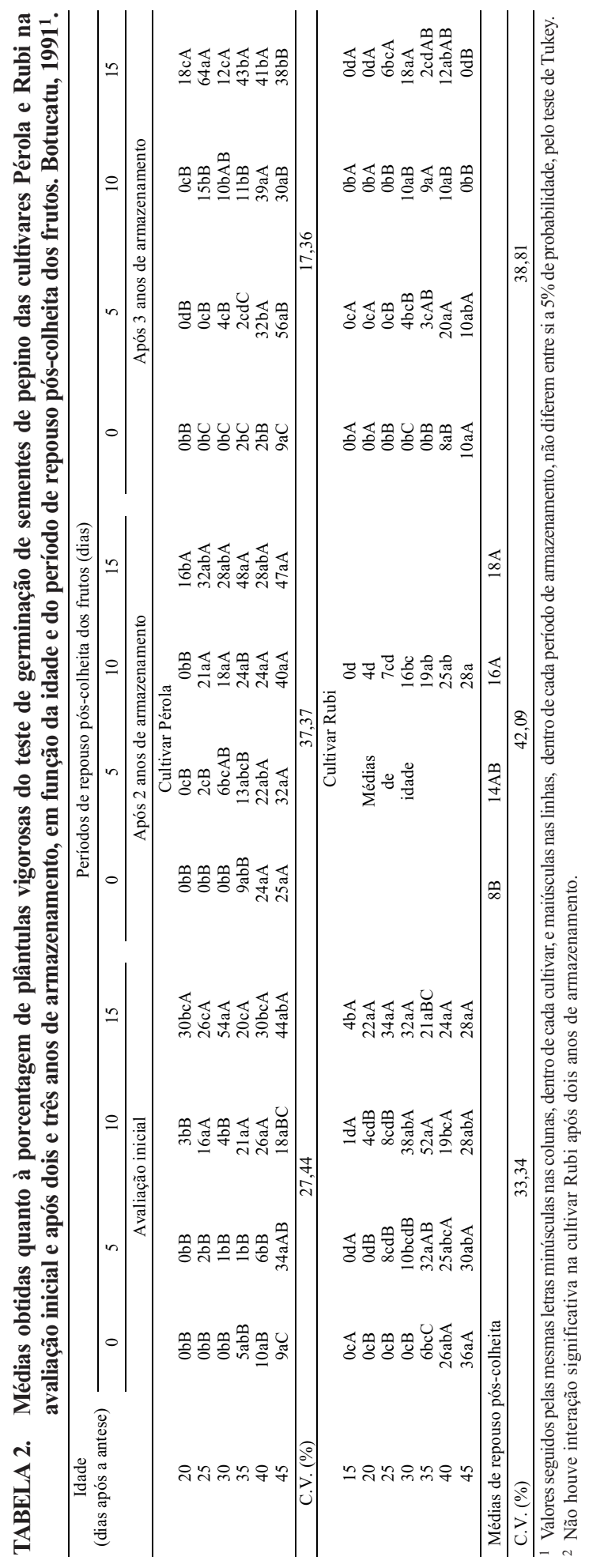

mazenadas, deve-se notar que a porcentagem de sementes germináveis (Tabela 3 ), aqui considerada como a somatória de plântulas normais e anormais, ou seja, a porcentagem de sementes que chegaram a emitir raiz primária, não apresentou as diferenças acima referidas. Em diversos estudos botânicos, a emissão da raiz primária, ou de outra estrutura do eixo embrionário, é a característica considerada para a avaliação da porcentagem de germinação (Metivier, 1979; Mayer \& Poljakoff-Mayber, 1982; Labouriau, 1983). Esse critério é descrito por Labouriau (1983) como "critério botânico" da germinação. Pelos resultados obtidos no presente trabalho, pode-se verificar, confrontando-se as Tabelas 1 e 2 com a Tabela 3, que tal característica não poderia ser utilizada para se diferenciar lotes de sementes quanto à qualidade fisiológica, apesar de tal diferença ter se mostrado evidente quando analisadas a porcentagem de germinação e a porcentagem de plântulas vigorosas (Tabelas 1 e 2, respectivamente). Esse "critério botânico", portanto, poderia apenas ser empregado para separar os eventos "germinação", propriamente dita, e "desenvolvimento". Entretanto, é interessante observar que tanto Labouriau (1983) quanto Mayer \& Poljakoff-Mayber (1982) relataram a dificuldade em se delimitar, ao menos visualmente, o final da germinação e o início do desenvolvimento do embrião e da plântula. Labouriau (1983) menciona, inclusive, que em alguns casos é necessário um acompanhamento do crescimento do embrião para concluir sobre sua capacidade em desenvolver uma nova planta. Mayer \& Poljakoff-Mayber (1982), por sua vez, vão mais além em sua análise quanto à utilização do "critério botânico" da germinação, relatando que a protrusão da radícula ou de outra parte do embrião, através do tegumento da semente, é, na realidade, produto de divisão e/ou expansão celular, caracterizando também, portanto, desenvolvimento de embrião e não germinação propriamente dita. Assim, apesar de não se constituir o objetivo principal, o presente trabalho mostra resultados que evidenciam a necessidade de cuidados na utilização do "critério botânico" da germinação para a separação de lotes de sementes quanto à qualidade fisiológica.

A primeira contagem do teste de germinação apresentou valores sem uma tendência clara de comportamento, principalmente após três anos de armazenamento das sementes, quando os valores já haviam se tornado nulos em sua grande maioria (Tabela 4). Na época, os poucos tratamentos que 
TABELA 3. Médias obtidas em relação à porcentagem de sementes germináveis do teste de germinação de sementes de pepino das cultivares Pérola e Rubi na avaliação inicial e após dois e três anos de armazenamento, em função da idade e do período de repouso pós-colheita dos frutos. Botucatu, 1991'.

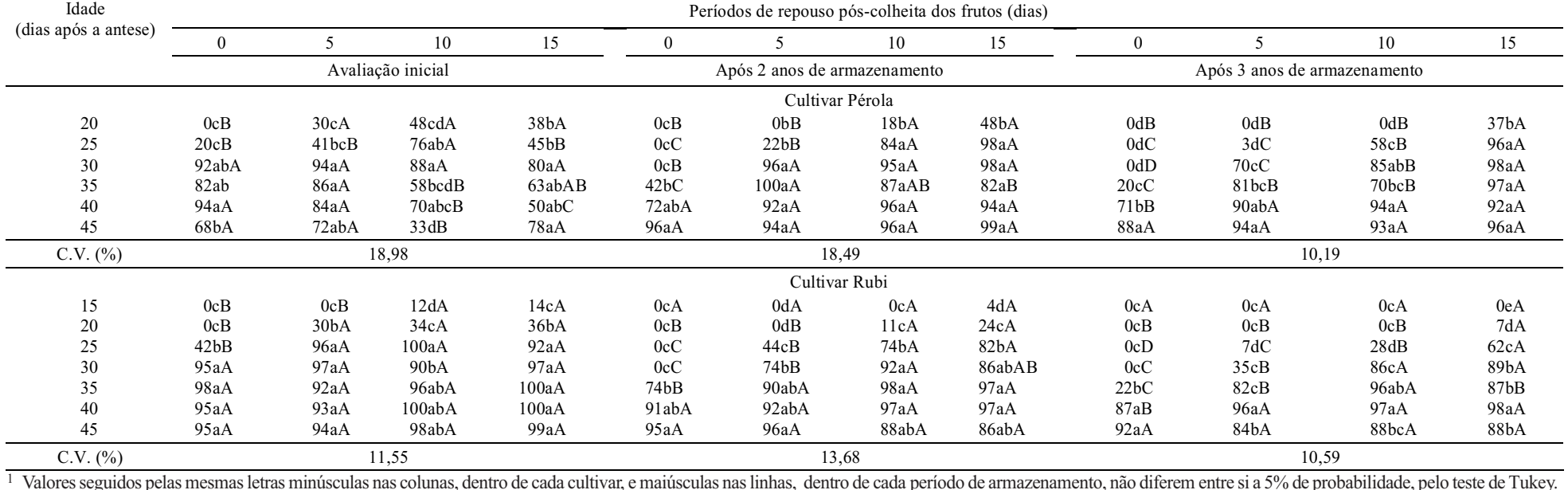

TABELA 4. Médias obtidas quanto a plântulas normais na primeira contagem (4 dias) do teste de germinação de sementes de pepino das cultivares Pérola e Rubi na avaliação inicial e após dois e três anos de armazenamento, em função da idade e do período de repouso pós-colheita dos frutos. Botucatu, $1991{ }^{1}$.

\begin{tabular}{|c|c|c|c|c|c|c|c|c|c|c|c|c|}
\hline \multirow{3}{*}{$\begin{array}{c}\text { Idade } \\
\text { (dias após a antese) }\end{array}$} & \multicolumn{12}{|c|}{ Períodos de repouso pós-colheita dos frutos (dias) } \\
\hline & 0 & 5 & 10 & 15 & 0 & 5 & 10 & 15 & 0 & 5 & 10 & 15 \\
\hline & \multicolumn{4}{|c|}{ Avaliação inicial } & \multicolumn{4}{|c|}{ Após 2 anos de armazenamento ${ }^{2}$} & \multicolumn{4}{|c|}{ Após 3 anos de armazenamento } \\
\hline & & & & & & & Pérola & & & & & \\
\hline 20 & $0 \mathrm{aB}$ & obB & 0cB & $19 \mathrm{bA}$ & & & 3a & & $0 \mathrm{aA}$ & obA & obA & $0 \mathrm{cA}$ \\
\hline 25 & $0 \mathrm{aB}$ & obB & 4abcB & $16 \mathrm{bA}$ & & Médias & $7 \mathrm{a}$ & & $0 \mathrm{aB}$ & obB & obB & $4 \mathrm{aA}$ \\
\hline 30 & $0 \mathrm{aB}$ & $1 \mathrm{bB}$ & $2 \mathrm{bC}$ & $39 \mathrm{aA}$ & & de & $8 \mathrm{a}$ & & $0 \mathrm{aA}$ & obA & obA & $0 \mathrm{cA}$ \\
\hline 35 & $1 \mathrm{aB}$ & obB & $5 \mathrm{abcAB}$ & 10bA & & idade & 13a & & $0 \mathrm{aA}$ & obA & obA & $0 \mathrm{cA}$ \\
\hline 40 & $4 \mathrm{aB}$ & $4 a b B$ & $14 \mathrm{aAB}$ & 17bA & & & $9 \mathrm{a}$ & & $0 \mathrm{aB}$ & obB & $4 \mathrm{aA}$ & $2 \mathrm{bA}$ \\
\hline 45 & $2 \mathrm{aB}$ & $14 \mathrm{aA}$ & $10 \mathrm{abAB}$ & $10 \mathrm{bAB}$ & & & $10 \mathrm{a}$ & & $0 \mathrm{aB}$ & $3 \mathrm{aA}$ & $5 \mathrm{aA}$ & $0 \mathrm{cB}$ \\
\hline \multicolumn{5}{|c|}{ Médias de repouso pós-colheita } & \multirow{2}{*}{\multicolumn{4}{|c|}{$\begin{array}{ll} & 8 \mathrm{AB} \\
71,96 & \end{array}$}} & & & & \\
\hline C.V. $(\%)$ & \multicolumn{4}{|c|}{36,93} & & & & & \multicolumn{4}{|c|}{34,14} \\
\hline & & & & & \multicolumn{4}{|c|}{ Cultivar Rubi } & \\
\hline 15 & $0 \mathrm{cA}$ & 0dA & OdA & $3 \mathrm{cA}$ & & & $0 \mathrm{~d}$ & & $0 \mathrm{aA}$ & $0 \mathrm{aA}$ & ObA & OaA \\
\hline 20 & $0 \mathrm{cB}$ & $0 \mathrm{~dB}$ & $2 \mathrm{~dB}$ & $22 \mathrm{bA}$ & & & $1 \mathrm{~cd}$ & & $0 \mathrm{aA}$ & $0 \mathrm{aA}$ & obA & OaA \\
\hline 25 & $0 \mathrm{cC}$ & $10 \mathrm{cdB}$ & $29 \mathrm{bcA}$ & $48 \mathrm{aA}$ & & & $3 \mathrm{~cd}$ & & $0 \mathrm{aA}$ & $0 \mathrm{aA}$ & obA & $2 \mathrm{aA}$ \\
\hline 30 & $0 \mathrm{cC}$ & $36 \mathrm{aB}$ & $68 \mathrm{aA}$ & $30 \mathrm{abB}$ & & & $13 \mathrm{bc}$ & & $0 \mathrm{aA}$ & $0 \mathrm{aA}$ & $0 \mathrm{bA}$ & $0 \mathrm{aA}$ \\
\hline 35 & $18 \mathrm{bB}$ & $48 \mathrm{aAB}$ & $50 \mathrm{abA}$ & $18 \mathrm{bB}$ & & & $25 \mathrm{ab}$ & & $0 \mathrm{aB}$ & $0 \mathrm{aB}$ & $18 \mathrm{aA}$ & $0 \mathrm{aB}$ \\
\hline 40 & $46 a A$ & $18 \mathrm{bcB}$ & $22 \mathrm{cB}$ & 30abAB & & & $33 a$ & & $0 \mathrm{aA}$ & $0 \mathrm{aA}$ & $0 \mathrm{bA}$ & $0 \mathrm{aA}$ \\
\hline 45 & $54 \mathrm{aA}$ & $30 \mathrm{abB}$ & $32 \mathrm{bcB}$ & $28 \mathrm{abB}$ & & & $21 \mathrm{ab}$ & & $0 \mathrm{aA}$ & $0 \mathrm{aA}$ & $0 \mathrm{bA}$ & $0 \mathrm{aA}$ \\
\hline \multirow{2}{*}{\multicolumn{4}{|c|}{ Médias de repouso pós-colheita }} & & $10 \mathrm{~A}$ & $14 \mathrm{~A}$ & $14 \mathrm{~A}$ & $18 \mathrm{~A}$ & & & & \\
\hline & & & & & \multicolumn{4}{|c|}{65,50} & \multicolumn{4}{|c|}{31,88} \\
\hline
\end{tabular}

1 Valores seguidos pelas mesmas letras minúsculas nas colunas, dentro de cada cultivar, e maiúsculas nas linhas, dentro de cada período de armazenamento, não diferem entre si a $5 \%$ de probabilidade, pelo teste de Tukey. 2 Não houve interação significativa nos dois anos de armazenamento. 
apresentaram algumas plântulas normais nessa primeira contagem estavam distribuídos de forma errática. Além disso, o teste gerou os maiores coeficientes de variação, chegando a superar 70\% quando transformados. Tais observações são concordantes com Barbedo et al. (1994) quanto às dificuldades apresentadas por esse teste para se verificar o vigor de sementes de pepino, sendo muito irregular para detectar as diferenças existentes entre os materiais e o mais influenciado pelas variáveis não controladas. Entretanto, analisando-se tal teste como indicador da diminuição na velocidade da germinação, com o armazenamento, pode-se verificar que essa característica é, de fato, mais sensivelmente detectada no processo de deterioração que a porcentagem de germinação, conforme observou Nerson (1991) em algumas cucurbitáceas.

\section{CONCLUSÕES}

1. O potencial de armazenamento de sementes de pepino é tanto maior quanto mais próximas estiverem as sementes do seu ponto de maturidade fisiológica no momento da colheita.

2. As sementes podem atingir a maturidade fisiológica no interior dos frutos já colhidos, desde que sejam respeitados um período mínimo de permanência dos frutos na planta-mãe e um período mínimo de repouso pós-colheita.

\section{REFERÊNCIAS}

ALI, N.; SKIRVIN, R.; SPLITTSTOESSER, W.E.; GEORGE, W.L. Germination and regeneration of plants from old cucumber seed. HortScience, v.26, n.7, p.917-918, 1991.

ALVARENGA, E.M.; SILVA, R.F.; ARAÚJO, E.F.; CARDOSO, A.A. Influência da idade e armazenamento pós-colheita dos frutos na qualidade de sementes de melancia. Horticultura Brasileira, Brasília, v.2, n.2, p.5-8, 1984.

ALVARENGA, E.M.; SILVA, R.F.; ARAÚJO, E.F.; LEIRO, L.S. Maturação fisiológica de sementes de abóbora italiana. Revista Brasileira de Sementes, Brasília, v.13, n.2, p.147-150, 1991.
ARAÚJO, E.F.; MANTOVANI, E.C.; SILVA, R.F. Influência da idade e armazenamento dos frutos na qualidade de sementes de abóbora. Revista Brasileira de Sementes, Brasília, v.4, n.1, p.77-87, 1982.

BARBEDO, C.J.; NAKAGAWA, J.; BARBEDO, A.S.C.; ZANIN, A.C.W. Influência da idade e do período de repouso pós-colheita de frutos na qualidade fisiológica de sementes de pepino cv. Rubi. Horticultura Brasileira, Brasília, v.12, n.2, p.118-124, 1994.

BEWLEY, J.D.; BLACK, M. Seeds: physiology of development and germination. New York: Plenum Press, 1985. 367p.

BRASIL. Ministério da Agricultura. Departamento Nacional de Produção Vegetal. Regras para análise de sementes. Brasília, 1976. 188p.

CARVALHO, N.M.; NAKAGAWA, J. Sementes: ciência, tecnologia e produção. 2.ed. Campinas: Fund. Cargill, 1983. 429p.

DEMIR, I.; ELLIS, R.H. Changes in potential seed longevity and seedling growth during seed development and maturation in marrow. Seed Science Research, v.3, n.4, p.247-257, 1993.

EGUCHI, T.; OSHIKA, Y.; YAMADA, H. Studies on the effect of maturity on longevity in vegetable seeds. Bulletin of the National Institute of Agricultural Sciences, Series E, v.7 p.145-165, 1958.

GEORGE, R.A.T. Vegetable seed production. New York: Longman, 1985.318p.

LABOURIAU, L.G. A germinação das sementes. Washington, DC: OEA, 1983. 174p.

MAYER, A.M.; POLJAKOFF-MAYBER, A. The germination of seeds. 3.ed. Oxford: Pergamon Press, 1982. $211 \mathrm{p}$.

METIVIER, J.R. Dormência e germinação. In: FERRI, M.G. (Coord.). Fisiologia Vegetal. São Paulo: EPU, 1979. v.2, p.343-392.

NERSON, H. Fruit age and seed extraction procedures affect germinability of cucurbit seeds. Seed Science and Technology, v.19, n.1, p.185-195, 1991.

NERSON, H.; PARIS, H.S. Effects of fruit age, fermentation and storage on germination of cucurbit seeds. Scientia Horticulturae, Amsterdam, v.35, n.1/2, p.15-26, 1988. 
NIENHUIS, J.; LOWER, R.L. The effects of fermentation and storage time on germination of cucumber seeds at optimal and suboptimal temperatures. Cucurbit Genetics Cooperative Annual Reports. v.4, p.1316, 1981.

PEDROSA, J.F.; OLIVEIRA, G.M.; BEZERRA NETO, F.; MONTEIRO, M.R. Influência da idade e armazenamento do fruto na produção e qualidade de sementes de Cucurbita maxima x C. moschata. Horticultura Brasileira, Brasília, v.5, n.2, p.1517, 1987.

SHIFRISS, O.; GEORGE JUNIOR, W.L. Delayed germination and flowering in cucumbers. Nature, v.206, n.4982, p.424-425, 1965.

TOLEDO, F.F.; MARCOS FILHO, J. Manual das sementes: tecnologia da produção. São Paulo: Agronômica Ceres, 1977. 224p.
VIGGIANO, J. Produção de sementes de cucurbitáceas. In: CASTELLANE, P.D.; NICOLOSI, W.M.; HASEGAWA, M. Produção de sementes de hortaliças. Jaboticabal: FCAV/FUNEP, 1990. p.95-112.

WATTS, V.M. Rest period in cucumber seeds. Proceedings of the American Society for Horticultural Science, v.36, p.652-654, 1938.

WELBAUM, G.E.; BRADFORD, K.J. Water relations of seed development and germination in muskmelon (Cucumis melo L.). Journal of Experimental Botany, Oxford, v.42, n.242, p.1137-1145, 1991.

ZOBEL, M.P.; DAVIS, G.N. Effect of the number per plant on the yield and quality of cucumber seed. Proceedings of the American Society for Horticultural Science, v.53, p.355-358, 1949. 